\title{
STRATEGI MENINGKATKAN KEUNGGULAN BERSAING PADA PT RESTU BUMI LESTARI
}

\author{
Hendri Herman \\ Dosen Universitas Putera Batam \\ email: hendrihermanbatam@gmail.com
}

\begin{abstract}
This study aims to determine the strategies that can be carried out by companies in increasing competitive advantage. The object of this study is PT Restu Bumi Lestari with 45 respondents. The research data was obtained using a questionnaire. The results of this study are that prices significantly influence competitive advantage, service quality significantly influences competitive advantage, and price and service quality simultaneously have a significant effect on competitive advantage.
\end{abstract}

Keywords: price, service quality, competitive advantage

\section{PENDAHULUAN}

Keunggulan kompetitif merupakan sejauh mana sebuah organisasi mampu menciptakan posisi dimana dapat mempertahankan pasar selama masih adanya pesaing. Perusahaan menciptakan keunggulan kompetitif melalui kemampuan kompetitif atau prioritas yang didefenisikan sebagai preferensi strategis atau dimensi dimana perusahaan memilih untuk bersaing di pasar yang ditargetkan (Russell \& Millar, 2014)

Perusahaan yang ingin menguasai pasar tentu berusaha agar perusahaan mereka memiliki keunggulan bersaing dibanding perusahaan sejenis yang menjadi pesaing-pesaingnya. Untuk memiliki keunggulan bersaing, maka perusahaan harus berbenah diri agar klien-klien tetap menggunakan jasa/produk yang dihasilkan oleh perusahaan.

Porter (1990) dalam (Setiawan, 2012) menjelaskan bahwa keunggulan bersaing (competitive advantage) adalah jantung kinerja pemasaran untuk menghadapi persaingan. Keunggulan bersaing diartikan sebagai strategi benefit dari perusahaan yang melakukan kerjasama untuk menciptakan kenggulan bersaing yang lebih efektif dalam pasarnya. Strategi ini harus didesain untuk mewujudkan keunggulan bersaing yang terus menerus sehingga perusahaan dapat mendominasi baik di pasar lama maupun pasar baru. Keunggulan bersaing pada dasarnya tumbuh dari nilai-nilai manfaat yang diciptakan oleh perusahan bagi para pembelinya. Pelanggan umumnya lebih memilih membeli produk yang memiliki nilai lebih dari yang diinginkan atau diharapkannya. Namun demikian, nilai tersebut juga akan dibandingkan dengan harga yang ditawarkan

Banyak konsumen yang menginginkan harga yang ditawarkan oleh para penyedia jasa/produk adalah harga yang terjangkau tetapi tidak mengurangi kualitas. Maka dari itulah, perlunya strategi perusahaan dalam menetapkan harga yang akan ditawarkan kepada calon konsumen. Terlebih lagi jika perusahaan adalah perusahaan yang terbilang baru. Penetapan harga harus menjadi pertimbangan utama bagi para perusahaan.

Pelayanan yang diberikan kepada konsumen menjadi cara yang dapat dilakukan oleh perusahaan agar konsumen betah sehingga akan menggunakan kembali jasa/ produk perusahaan. Pelayanan yang diberikan kepada konsumen tentunya adalah pelayanan yang berkualitas. Menurut Parasuraman dalam (Adam, 2015) menyatakan bahwa kualitas pelayanan merupakan pedoman dasar bagi pemasaran jasa, karena ini merupakan produk yang dipasarkan adalah suatu kinerja (yang berkualitas) dan kinerja juga yang akan dibeli oleh pelanggan.

Saat persaingan bisnis semakin ketat, dimana banyak perusahaan-perusahaan sejenis yang menjadi pesaing. Maka perusahaan harus mampu menjawab keinginan pasar. Perusahaan 
harus mampu memberikan harga yang kompetitif untuk mendapatkan pelanggan dengan tetap memberikan kualitas pelayanan yang baik.

Penelitian ini dilakukan pada PT Restu Bumi Lestari. PT Restu Bumi Lestari ini bergerak di bidang galangan kapal. Peneli melakukan penelitian dengan judul strategi meningkatkan keunggulan bersaing pada PT Restu Bumi Lestari.

\section{TINJAUAN PUSTAKA}

Harga

Harga adalah jumlah uang yang harus dibayar pelanggan untuk memperoleh produk tersebut. Harga adalah satu-satunya unsur bauran pemasaran yang menghasilkan pendapatan penjualan karena unsur yang lain adalah mengeluarkan biaya (Tan, 2011).

Menurut Tjiptono (2006) dalam (Umaternate, 2014) dikatakan bahwa harga merupakan pernyataan nilai dari suatu produk ( $a$ statement of value). Harga juga merupakan elemen bauran pemasaran yang paling fleksibel. Tidak seperti fitur produk dan komitmen penyalur, harga dapat berubah dengan cepat (Kotler dan Armsrong, 2008 dalam (Umaternate, 2014)

Indikator yang digunakan untuk harga adalah sebagai berikut (Tjiptono, 2006):

(1) Keterjangkauan harga

(2) Diskon/ potongan harga

(3) Cara pembayaran

(4) Negosiasi

(5) Garansi

\section{Kualitas Pelayanan}

Konsep kualitas pelayanan merupakan faktor penilaian yang merefleksikan persepsi konsumen terhadap lima dimensi fisik dan kinerja layanan. Menurut (Supranto, 2006) kualitas pelayanan merupakan sesuatu yang harus dikerjakan oleh penyedia jasa dengan baik. Kualitas pelayanan seperti yang dirasakan oleh para konsumen, berasal dari suatu perbandingan antara apa yang ditawarkan oleh suatu perusahaa pelayanan yaitu hargapan dan dengan persepsi mereka tentang kinerja pemberi jasa.

Sekarang ini, pelanggan semakin pintar, mereka sangat kritis sehingga para pelaku bisnis harus mapu memberikan pelayanan yang sesuai dengan harapan pelanggan. Sedikit saja penyimpangan, misalnya pelayanan tidak sesuai dengan yang diharapkan, para pelanggan akan menilai jelek (Barata, 2006) dalam (Herman, 2018)

Indikator yang digunakan untuk mengukur kualitas pelayanan adalah:

(1) Tangible

(2) Reability

(3) Responsiveness

(4) Assurance

(5) Emphaty

\section{Keunggulan Bersaing}

(Dirgantoro, 2010) Keunggulan bersaing merupakan perkembangan dari nilai yang mampu diciptakan persuahaan untuk pembelinya. Berdasarkan defenisi di atas, maka keunggulan bersaing tidak dapat dipahami dengan memandang perusahaan sebagai suatu keseluruhan. Keunggulan bersaing berasal dari banyak aktivitas berlainan yang dilakukan perusahaan dalam mendesain, memproduksi, memasarkan, menyerahkan, mendukung produknya

Indikator keunggulan bersaing adalah:

(1) Keunikan produk

(2) Kualitas produk

(3) Harga 


\section{Kerangka Pemikiran}

Kerangka pemikiran dalam penelitian ini dapat dilihat pada gambar berikut:

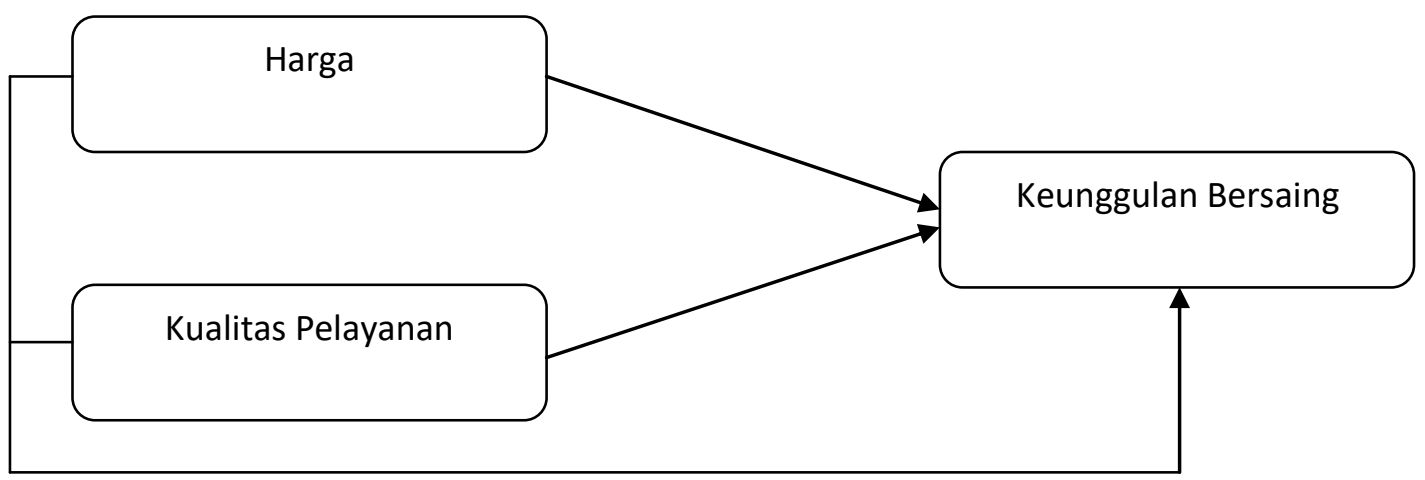

\section{Hipotesis}

Hipotesis penelitian ini adalah sebagai berikut:

1) Harga berpengaruh signifikan terhadap keunggulan bersaing

2) Kualitas pelayanan berpengaruh signifikan terhadap keunggulan bersaing

3) Harga dan kualitas pelayanan secara simultan berpengaruh signifikan terhadap keunggulan bersaing.

\section{METODE}

Populasi dalam penelitian ini adalah sebanyak 45 responden. Sampel dalam penelitian ini menggunakan teknik sampel jenuh, dimana semua populasi dalam penelitian ini dijadikan sampel. Teknik pengumpulan data dilakukan dengan penyebaran kuisioner. Data akan diuji dengan menggunakan uji validitas, uji reliabilitas, uji asumsi klasik dan dengan uji hipotesis.

\section{HASIL DAN PEMBAHASAN}

\section{Uji Validitas}

Hasil uji validitas dalam penelitian ini dapat dilihat pada tabel berikut:

Tabel 1. Hasil Uji Validitas Harga

\begin{tabular}{|l|l|l|l|l|}
\hline No & Item & R hitung & R tabel & Kesimpulan \\
\hline 1 & X.1.1 & 0.552 & 0.2876 & Valid \\
\hline 2 & X.1.2 & 0.735 & 0.2876 & Valid \\
\hline 3 & X.1.3 & 0.653 & 0.2876 & Valid \\
\hline 4 & X.1.4 & 0.733 & 0.2876 & Valid \\
\hline 5 & X.1.5 & 0.817 & 0.2876 & Valid \\
\hline
\end{tabular}

Berdasarkan tabel di atas, dapat dilihat bahwa nilai $\mathrm{r}$ hitung masing-masing variabel harga lebih besar dari nilai $r$ tabel (0.2876). Sehingga dapat disimpulkan bahwa semua item dalam variabel harga adalah valid.

Tabel 2. Hasil Uji Validitas Kualitas Pelayanan

\begin{tabular}{|l|l|l|l|l|}
\hline No & Item & R hitung & R tabel & Kesimpulan \\
\hline 1 & X.1.1 & 0.652 & 0.2876 & Valid \\
\hline 2 & X.1.2 & 0.535 & 0.2876 & Valid \\
\hline 3 & X.1.3 & 0.453 & 0.2876 & Valid \\
\hline 4 & X.1.4 & 0.633 & 0.2876 & Valid \\
\hline 5 & X.1.5 & 0.717 & 0.2876 & Valid \\
\hline
\end{tabular}


Berdasarkan tabel di atas, dapat dilihat bahwa nilai $\mathrm{r}$ hitung masing-masing variabel kualitas pelayanan lebih besar dari nilai $r$ tabel (0.2876). Sehingga dapat disimpulkan bahwa semua item dalam variabel kualitas pelayanan adalah valid.

Tabel 3. Hasil Uji Validitas Keunggulan Bersaing

\begin{tabular}{|l|l|l|l|l|}
\hline No & Item & R hitung & R tabel & Kesimpulan \\
\hline 1 & Y.1 & 0.816 & 0.2876 & Valid \\
\hline 2 & Y.2 & 0.606 & 0.2876 & Valid \\
\hline 3 & Y.3 & 0.721 & 0.2876 & Valid \\
\hline
\end{tabular}

Berdasarkan tabel di atas, dapat dilihat bahwa nilai $r$ hitung masing-masing variabel keunggulan bersaing lebih besar dari nilai $r$ tabel (0.2876). Sehingga dapat disimpulkan bahwa semua item dalam variabel keunggulan bersaing adalah valid

\section{Uji Reliabilitas}

Tabel 4. Hasil Uji Reliabilitas

Hasil uji reliabilitas dalam penelitian ini dapat dilihat pada tabel berikut:

\begin{tabular}{|l|l|l|l|}
\hline No & Variabel & Cronbach Alpha & Kesimpulan \\
\hline 1 & Harga & 0,877 & Reliabel \\
\hline 2 & Kualitas Pelayanan & 0.633 & Reliabel \\
\hline 3 & Keungulan Bersaing & 0.874 & Reliabel \\
\hline
\end{tabular}

Berdasarkan tabel di atas, dapat dilihat bahwa masing-masing nilai cronbach alpha pada variabel harga, kualitas pelayanan dan keunggulan bersaing sebesar $0.877,0.633$ dan 0.874 . nilai cronbach alpha ini lebih besar dari 0.6. sehingga disimpulkan bahwa item-item dalam variabel penelitian ini adalah reliable.

\section{Uji Asumsi Klasik}

Uji Normalitas

Tabel 5 Uji Normalitas

One-Sample Kolmogorov-Smirnov Test

\begin{tabular}{|c|c|c|}
\hline & & $\begin{array}{c}\text { Standardized } \\
\text { Residual }\end{array}$ \\
\hline $\begin{array}{l}\text { N } \\
\text { Normal Parameters } \\
\text { Most Extreme Differences } \\
\text { Kolmogorov-Smirnov Z } \\
\text { Asymp. Sig. (2-tailed) }\end{array}$ & $\begin{array}{l}\text { Mean } \\
\text { Std. Deviation } \\
\text { Absolute } \\
\text { Positive } \\
\text { Negative }\end{array}$ & $\begin{array}{r}45 \\
.0000000 \\
.96076892 \\
.115 \\
.064 \\
-.115 \\
.599 \\
.766 \\
\end{array}$ \\
\hline
\end{tabular}

a. Test distribution is Normal.

b. Calculated from data.

Dari tabel di atas, dapat dilihat bahwa, nilai Asymp. Sig (2-tailed) bernilai 0,766. Nilai ini lebih besar dari 0,05. Sehingga dapat disimpulkan bahwa data dalam penelitian ini memiliki sebaran normal 


\section{Uji Multikolinearitas}

Tabel 6 Uji Multikolinearitas Coefficients $^{\mathrm{a}}$

\begin{tabular}{|ll|r|r|}
\hline \multirow{2}{*}{ Model } & \multicolumn{2}{|c|}{ Collinearity Statistics } \\
\cline { 2 - 3 } & Tolerance & \multicolumn{1}{c|}{ VIF } \\
\hline \multirow{2}{*}{1} & Harga & .832 & 1.002 \\
& Kualitas Pelayanan & .832 & 1.002 \\
& Keunggulan Bersaing & .832 & 1.002 \\
\hline
\end{tabular}

a. Dependent Variable: Perubahan Laba

Dari tabel di atas, dapat dilihat bahwa nilai VIF masing-masing variabel sebesar 1.002. nilai VIF ini berada dibawah nilai 10. Sehingga dapat dikatakan bahwa model dalam penelitian ini tidak terjadi multikolinearitas.

\section{Uji Heteroskedastisitas}

Tabel 7 Uji Heteroskedastisitas

Coefficients $^{a}$

\begin{tabular}{|rl|r|r|r|r|r|}
\hline Model & \multicolumn{2}{|c|}{ Unstandardized Coefficients } & $\begin{array}{c}\text { Standardized } \\
\text { Coefficients }\end{array}$ & \multirow{2}{*}{ Sig. } \\
\cline { 3 - 5 } & \multicolumn{1}{|c|}{$\mathrm{B}$} & Std. Error & \multicolumn{1}{|c|}{ Beta } & & \\
\hline \multirow{2}{*}{1} & $-1.013 \mathrm{E}-013$ & 3.830 & & .000 & 1.000 \\
& (Constant) & .000 & .250 & .000 & .000 & 1.000 \\
& Harga & .000 & .340 & .000 & .000 & 1.000 \\
\hline
\end{tabular}

a. Dependent Variable: Abresid

Dari tabel di atas, dapat dilihat bahwa nilai sig. masing-masing variabel bernilai 1.000 , nilai ini lebih besar dari 0.05 , sehingga dapat disimpulkan bahwa dalam penelitian ini tidak terjadi gejala heteroskedastisitas.

\section{Uji Hipotesis}

Uji t (Parsial)

Hasil uji t dalam penelitian ini dapat dilihat pada tabel berikut ini:

Tabel 8 Uji t

Coefficients $^{\mathrm{a}}$

\begin{tabular}{|c|c|c|c|c|c|c|}
\hline \multirow{2}{*}{\multicolumn{2}{|c|}{ Model }} & \multicolumn{2}{|c|}{ Unstandardized Coefficients } & \multirow{2}{*}{$\begin{array}{c}\begin{array}{c}\text { Standardized } \\
\text { Coefficients }\end{array} \\
\text { Beta }\end{array}$} & \multirow[t]{2}{*}{$\mathrm{t}$} & \multirow[t]{2}{*}{ Sig. } \\
\hline & & $\mathrm{B}$ & Std. Error & & & \\
\hline \multirow{3}{*}{1} & (Constant) & 3.249 & .134 & & 9.325 & .000 \\
\hline & Harga & .050 & .052 & .264 & 3.353 & .004 \\
\hline & Kualitas Pelayanan & .018 & .012 & .133 & 6.683 & .000 \\
\hline
\end{tabular}

a. Dependent Variable: Perubahan Laba

1. Harga terhadap keunggulan bersaing

Dari tabel di atas, dapat dilihat bahwa, nilai signifikansi harga sebesar 0.004 , nilai signifikansi ini lebih kecil dari 0.05 . Sehingga dapat disimpulkan bahwa harga berpengaruh signifikan terhadap keunggulan bersaing. Hipotesis pertama diterima

2. Kualitas pelayanan terhadap keunggulan bersaing

Dari tabel di atas, dapat dilihat bahwa nilai signifikansi kualitas pelayanan sebesar 0.000 , nilai signifikansi ini lebih kecil dari 0.05 . Sehingga dapat disimpulkan bahwa 
kualitas pelayanan berpengaruh signifikan terhadap keunggulan bersaing. Hipotesis kedua diterima.

\section{Uji f (Simultan)}

Hasil uji f dalam penelitian ini dapat dilihat pada tabel berikut ini:

Tabel 9. Uji f

ANOVA $^{\mathrm{a}}$

\begin{tabular}{|rl|r|r|r|r|r|}
\hline Model & Sum of Squares & df & Mean Square & F & Sig. \\
\hline \multirow{2}{*}{1} & Regression & .216 & 2 & .108 & 9.242 & $.000^{\circ}$ \\
& Residual & 2.088 & 34 & .087 & & \\
& Total & 2.304 & 36 & & & \\
\hline
\end{tabular}

a. Dependent Variable: Keunggulan Bersaing

b. Predictors: (Constant), Harga, Kualitas Pelayanan

3. Harga dan kualitas pelayanan terhadap keunggulan bersaing

Dari tabel di atas, dapat dilihat bahwa nilai signifikansi sebesar 0.000 , nilai signifikansi ini lebih kecil dari 0.05. Sehingga dapat disimpulkan bahwa harga dan kualitas pelayanan secara simultan berpengaruh signifikan terhadap keunggulan bersaing. Hipotesis ketiga diterima

\section{Pembahasan}

1. Harga terhadap keunggulan bersaing

Harga merupakan hal yang dipertimbangkan oleh konsumen sebelum melakukan pembelian atau menggunakan jasa suatu perusahaan, hal ini dikarenakan banyak konsumen yang menginginkan untuk mendapatkan produk/ jasa yang diinginkan dengan harga terjangkau. Oleh karena itu, perusahaan perlu mempertimbangkan harga pada produk atau jasa yang ditawarkan ke konsumen. Cara seperti ini, dapat digunakan oleh perusahaan untuk memperoleh keunggulan bersaing. PT Restu Bumi Lestari perlu mempertimbangkan penetapan harga yang ditawarkan kepada konsumen mengingat, banyak pesaing yang bergerak dibidang yang sejenis, sehingga PT Restu Bumi Lestari dapat memenangkan persaingan

2. Kualitas pelayanan terhadap keunggulan bersaing

Pelayanan yang baik menjadi cerminan bagaimana perusahaan mengutamakan konsumennya. Konsumen akan jauh lebih senang jika perusahaan memberikan pelayanan yang baik. Konsumen dapat mengubah persepsi terhadap perusahaan dari kualitas pelayanan yang diberikan oleh perusahaan. Perusahaan yang memiliki kelengkapan prasarana, perusahaan yang mampu memberikan layanan secara akurat dan dapat dipercaya, perusahaan yang mampu merespon permintaan secara cepat dan tepat, perusahaan yang mampu memberikan rasa aman kepada konsumen, perusahaan yang mampu memahami masalah atau keluhan pelanggan terkait produk/ jasa yang digunakan, adalah perusahaan yang dapat memberikan kualitas pelayanan yang baik. PT Restu Bumi Lestari diharapkan dapat memberikan kualitas pelayanan yang baik bagi konsumen agar dapat meningkatkan keunggulan bersaing.

\section{SIMPULAN}

Simpulan dalam penelitian ini adalah sebagai berikut:

1. Harga berpengaruh signifikan terhadap keunggulan bersaing

2. Kualitas pelayanan berpengaruh signifikan terhadap keunggulan bersaing 
3. Harga dan kualitas pelayanan secara simultan berpengaruh signifikan terhadap keunggulan bersaing

\section{DAFTAR PUSTAKA}

Adam, M. (2015). Manajemen Pemasaran Jasa. Bandung: Alfabeta.

Barata, A. A. (2006). Dasar-Dasar Pelayanan Prima. Jakarta: PT Elex Media Komputindo.

Dirgantoro, C. (2010). Manajemen Stratejik Konsep, Kasus, dan Implementasi. Jakarta: Grasindo.

Herman, H. (2018). Strategi Meningkatkan Keunggulan Bersaing Melalui Kualitas Pelayanan Pada PT Putra Usaha Mandiri Kota Batam. Jurnal Akuntansi Barelang, 3(1), 57-63.

Russell, S. N., \& Millar, H. (2014). Exploring the Relationship Among Sustainable Manufacturing Practises, Business Performance and Competitive Advantage: Perspective From a Developing Economy. Journal of Management and Sustainability, 4(3), 37-54.

Setiawan, H. (2012). Pengaruh Orientasi Pasar, Orientasi Teknologi, dan Inovasi Produk Terhadap Keunggulan Bersaing Usaha Songket Skala Kecil di Kota Palembang. Jurnal Orasi Bisnis Edisi Ke-VIII, ISSN: 2085-1375, (November), 12-19.

Supranto, J. (2006). Pengukuran Tingkat Kepuasan Pelanggan Untuk Menaikkan Pangsa Pasar. Jakarta.

Tan, W. (2011). Manajemen Kualitas Jasa (1st ed.). Jakarta: Indeks.

Tjiptono, F. (2006). Manajemen Jasa. Yogyakarta: Andi.

Umaternate, M. (2014). Promosi, Harga dan Inovasi Pengaruhnya Terhadap Keputusan Pembelian Sepatu Futsal Nike di Toko Akbar Ali Sport Manado. Jurnal EMBA, Vol. 2, No. 2 Juni 2014. ISSN: 2303-1174, 2(2), 1381-1392. 